\title{
REFERENCES
}

1. Maitland Ramsay.-The Muscle of the Heart, the Intestinal Tract, the Iris and the Ciliary Body. Glasgow Med. Jl., Vol. VI, December, 1926. For abstract see Brit. Jl. of Ophthal., p. 306, 1927.

2. Ross, J -Brain, Vol. X, p. 333. 1887-88.

3. Head, Henry. - On Disturbances of Sensation with Special Reference to Visceral Disease. Brain, Vol. XVI, pp. 1-132. 1893; Vol. XVII, pp. 339-480, 1894 ; Vol. XIX, pp. 153-276, 1896.

4. Mackenzie, S'r Jas.-Angina Pectoris, 1923.

5. Poirier.-Traité d'Anatomie humaine. éd. III, Vol. V, fasc. 2, 1911

6. Whitnall, S. E.-Anatomy of the Human Orbit, p. 357.

7. Cannen and Washburn.-American Jl. of Physiol.. Vol. XXXIX, p. 441. 1912.

8. Sherrington.-The Integrative Action of the Nervous System, p. 12, 1906.

9. Hurst, A. F.-Brit. Med. Jl., Vol. I, p. 145, 1925.

10. Poulton, E. P.-Oliver-Sharpey Lectures on an Experimental Study of Certain Visceral Sensations. Lect. 1, Lancet, Vol. II, pp. 1223-1230 (December 15). 1928 ; Lect. 2, Vol. II, pp. 1277-1285 (December 22), 1928.

11. Lang.-Brit. Jl. of Ophthal., March, 1920.

12. Hess, C.-Die Anomalien der Refraktion und Akkommodation des Auges. Handbuch der gesamten Augenheilkunde, Band VIII, abt. 2.

13. Behan, Richard J - Pain : Its Origin, Conduction, Perception and Diagnostic Significance. New York, 1914.

14. Glasgow Eye Infirmary.-106th Annuai Report, 1929.

\section{SCHOOL MYOPIA*}

BY

\section{ARNOLD SORSBY}

LONDON

THE problem of school myopia is the problem of the development of myopia. This is a truism which needs stressing in these days when the conception of myopia as a physiological variation in a scale of refractive errors is becoming more established. If it was a fallacy to regard myopia as something distinct from other refractive conditions, it is equally fallacious to regard it purely as the antithesis of hypermetropia, in a graduated series in which refraction approaching emmetropia is the peak and centre.

Though it raises more problems than it solves, the work of Steiger and his school is undoubtedly the most important contribution to myopia that has been made during the present century. By pointing out that hypermetropia cannot be divorced from myopia, that emmetropia is an artificial conception, and myopia a continuation in an unbroken process, the whole of which can be represented by a curve corresponding to a theoretically derived

* Read in the Section of Ophthalmology at the Annual Meeting of the British Medical Association, Eastbourne, 1931. 
binomial curve, Steiger has emphasized the unity of the different spherical refractive conditions, and shown that at least some myopes must be regarded as normal variations occurring in any large group of people. In such view, long and short eyes get the same significance as tall and short individuals, i.e., they are variations around a common mean, the frequency declining progressively the more marked the variation.

It is, of course, true that all myopia cannot be thus explained. For, even the few curves available at present which deal with large numbers prove conclusively that the myopic side of such a curve shows lengthening, thus destroying the symmetry of the binomial curve. Scheerer and Betsch have, however, shown that if all cases which show myopic crescents and other fundus changes are excluded from such a curve, then its simple binomial nature again becomes apparent (Figs. 1 and 2). A similar result is obtained if all cases over $-6.0 \mathrm{D}$. are excluded (Tron). Arguing from such analyses a physiological and a pathological type of myopia have been suggested, the one being a normal variant in a large series, and differing in no essential way from its opposite on the hypermetropic side of the curve, and the other being a distinct aberration, determined by pathology, heredity or some other factor.

Another deviation from a calculated curve is shown by the curves established by Scheerer and Betsch for 12,000 eyes, and by Brown and Kronfeld for 5,000 eyes, for which it appears that emmetropic cases are in excess of their theoretical value (Fig. 1). The steep excursion could be criticized in the first series on the ground that

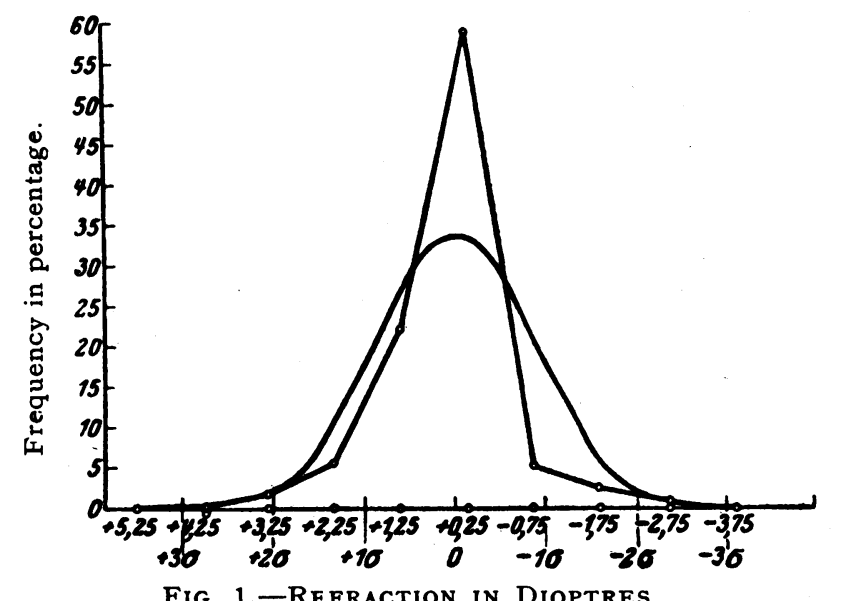

Comparison of the combined refraction curve of Scheerer and Betsch, with the theoretically derived binomial variation curve. (After Franceschetti, Kurzes Handbuch der Ophthalmologie, Bd. 1, S. 720). 


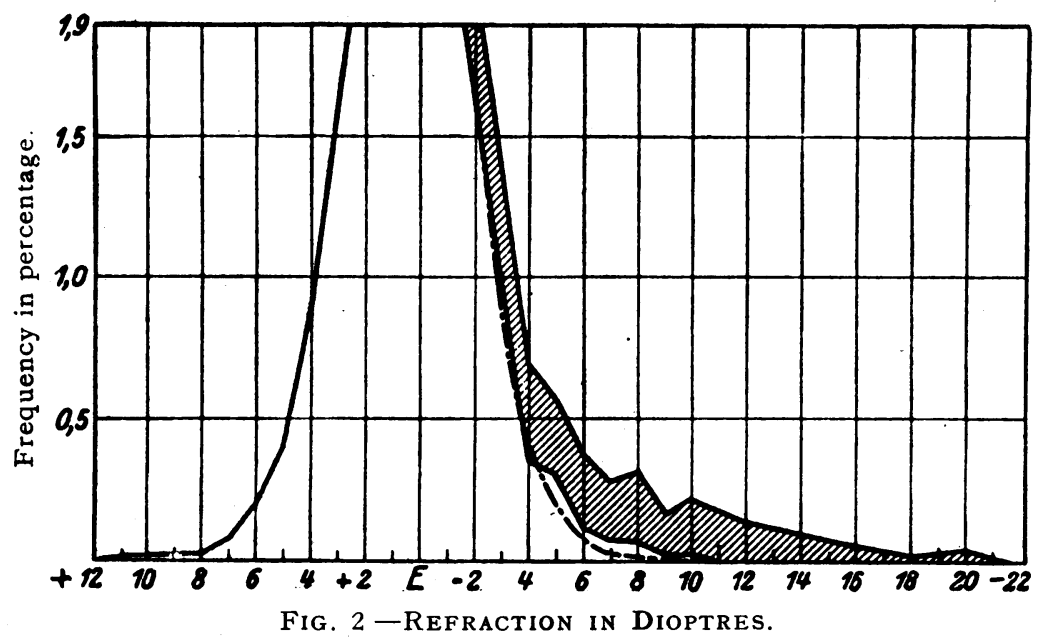

Frequency curve of refraction (after Scheerer) (Magnified base of the frequency curve shown in Fig. 1). The shaded area covers the cases of myopia with fundus changes. The broken line, '- $-{ }^{-} \cdot$ is the theoretically symmetrical curve on the myopic side.

the refractions were done without cycloplegia. In the second series, this objection does not hold. A process of "emmetropization" (Straub) has been called in to explain this anomaly, this process acting by a correlation of the different components of the total refraction (cornea, lens, axial length, etc.) to produce emmetropia, natural selection helping in that direction (Steiger).

It is clear that Steiger's hypothesis in an unmodified form, though it throws a flood of light on the problem of refraction, does not in itself explain all the refraction anomalies. But that there is some underlying unity which this theory stresses is strongly supported by the recent work of Tron, Vogt and others who have thrown grave doubts upon the old accepted view that myopia is essentially an increase of axial length and that the fundus changes associated with myopia are due to stretching of the posterior pole of the globe.

Tron has analysed 53 emmetropic eyes into their different refractive components, and has shown that not only is there no fixed corneal refraction for emmetropia, but that also the other factors show great variation. Thus, the total refractive power of the eye, that of the lens, of the cornea, and the axial length, all show definite excursion around a mean which is the apex of a binomial curve.

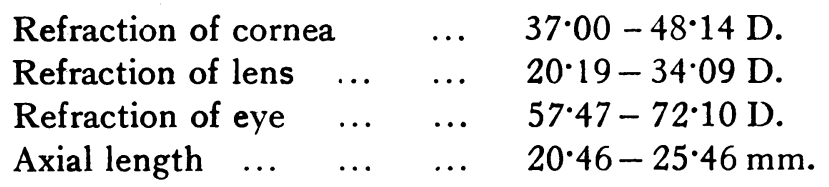


From these data it appears that the mean axial length of the emmetropic eye is $22.74 \mathrm{~mm}$., but as the normal variation is +3.72 , an emmetropic eye may be as short as $19.02 \mathrm{~mm}$. or as long as 26.46. Similarly, taking into account the normal variations in the different components of total refraction, it is possible to have a highly myopic eye actually shorter than an emmetropic or even hypermetropic eye. As Tron shows: an eye of $+4 \cdot 0 \mathrm{D}$. may have the same axial length as one of $-6.0 \mathrm{D}$.; likewise $+6.0 \mathrm{D}$. and $-9 \cdot 0 \mathrm{D}$. may result from the same axial length. It has been customary to ignore the variations in the lens in correlating axial length and corneal refraction, but the normal extremes of refraction between 20-34 D. show that this cannot be done. With these great excursions in the normal value of cornea, lens, axial length and total refraction, the notion that low myopia is due to elongation of the axis must be reconsidered, especialiy in that large class of low myopes who show no fundus changes at all. Tron shows that there is a positive correlation of medium magnitude between myopia and axial length. But this only proves that myopic eyes have more frequently long axes than hypermetropic eyes.

It is, therefore, not possible to draw any clear line of demarcation between myopia and hypermetropia, for a combination of normal variants can give emmetropia or a marked refractive error in either direction. When, in addition, doubt is thrown upon the so-called myopic fundus changes being due to stretching (Schnabel and Herrnheiser, v. Szily, Scheerer, Tron) many of the established criteria of distinction between hypermetropia and myopia begin to fail. v. Szily, junr., especially has stressed the developmental origin of many of these so-called myopic changes, and regards myopia in such cases as the result of developmental defects in the posterior segment. Tron reports a case of myopia of $20.0 \mathrm{D}$. with typical myopic fundus changes (associated with choroidal coloboma), in an eye of only $22.39 \mathrm{~mm}$. axial length.

The tendency to regard the lower degrees of myopia as physiological variations and the higher degrees as congenital or uncongenitally determined anomalies receives support from the views advanced by Vogt. Stressing the fact that the post-embryonic growth of the retina doubles its surface, Vogt holds that axial length accommodates itself to that growth; when the retina grows more rapidly than the sclera, the sclera becomes stretched, but the retina itself is not thinned in myopia, as can be shown by actual measurement (Vogt, Heine). Hereditary tendencies towards myopia or hypermetropia are explained by the hereditary tendency towards large or small retinae. The so-called myopic changes in the fundus Vogt regards as further hereditary-determined characteristics. They may be regarded as a sort of abiotrophic manifestation, and show considerable similarity to senile degeneration around 
the disc and macula. It is well to recall in this connection that experimental embryology has shown the paramount influence of the retina on the growth of the surrounding structures. Thus a transplanted optic vesicle will convert the ectoderm of the abdominal wall with which it is placed in contact into a lens, and a damaged retina at the posterior pole will check the axial growth of the eye. That the eye itself is not influenced in its growth by external conditions has been shown in the case of the salamander by Stone, who interchanged larval eyes of two species. The transplanted eyes followed closely the growth curves of their donor controls, but this did not apply to limbs similarly interchanged.

Much as recent work has clarified the issue, it cannot be said that all established factors are covered by the more modern views. Certainly, the problem of myopia has not been solved, as some continental authorities seem to believe. One bed-rock fact which recent work seems to ignore in its stressing of the essential unity of all spherical errors is the vastly different behaviours of the hypermetropic and myopic eye during school-life. The hypermetropic eye is for all practical purposes a stationary eye; the myopic eye is essentially progressive during these years. It is true, as the writer has shown elsewhere, that a considerable percentage of hypermetropic eyes are progressive during school-life, and a surprisingly large percentage of myopes show but little progression. Such facts help to stress the unity of refractive errors, but do not demolish the essentially difterent behaviour of the two types of eyes. Besides, it may well be that the progressive hypermetropic eye and the stationary myopic eye are but the beginning and end stages of that progressive process seen in myopia. To construct curves on one side of which is the hypermetropic eye and on the other side the myopic seems very much like constructing a curve of two different components. A physiological myopia in the sense of Steiger and of Tron should show exactly the same clinical behaviour as hypermetropic eyes. Much clinical experience will have to be explained away before such a contention can be proved.

Besides, it cannot be sufficiently emphasized that myopia develops during school life, and particularly after the age when the growth of the eye is regarded as being completed-the age of 8 years. Most school myopia becomes manifest at about the age of 12 years. If the growth of the eye has ceased by then, why should there be in a certain proportion of children a re-adjustment of axial length, or of the position or strength of the refracting media? This can hardly be a physiological process if it affects only a small percentage of children. A mass of problems have been thrown up by the work of Steiger and his school. What, for instance, is the refraction curve at the age of 8 years, i.e., at the completion of the growth of the eye, and before the onset of myopia introduces a new factor? 
What part do the cornea and the other refractive media play in cases of actively developing myopia? We know that the cornea and lens may have normal values in myopia, but did they have the same value before the onset of myopia?

It is unlikely that we shall solve the problem of myopia without intensive study in its breeding ground-the schools. The past refractive history of the child recently become myopic is still an unexplored field. Study for over a period of years of unselected children in the infants' schools, with their inevitable and unknown quota of ultimate myopes, will amply repay the labour, for school myopia remains to the key to the problem.

\title{
REFERENCES
}

Betsch.一Klin. Monatsbl.f. Augenheilk., Vol. LXXXII, p. 365, 1929.

Brown and Kronfeld.-Trans. XIII Internat. Ophthal. Congress, Vol. I, p. 87. 1929.

Scheerer.-Ber. 47 Verslg. dtsch. Ophthal. Ges. Heidelberg, p. 118, 1928.

Scheerer and Seitzer.-Klin. Monatsbl. f. Augenheilk., Vol. LXXXII, p. 511, 1929.

Schnabel and Herrnheisser.-Z. Heilk. ref. Nagel's Jahrsber., p. 436, 1895.

Sourasky (Sorsby).-Brit. Jl. of Ophthal., Vol. XII, p. 625, 1928.

Steiger.-Die Entstehung der sphärischen Refraktionen des Auges. Berlin, 1913.

Stone.-Jl. Exp. Zool., Vol. LV, p. 193, 1930.

Straub.-Arch.f. Augenheilk., Vol. XXVI, p. 336, 1893.

Szily, von.-Arch. f. Ophthal., Vol. CX, p. 183, 1922.

Tron.-Idem., Vol. CXXII, p. 1, 1929.

Idem., Vol. CXXVI, p. 454, 1931.

Vogt.-Ber. 44 Verslg. dtsch. Ophthal. Ges. Heidelberg, p. 67, 1924.

Klin. Monatsbl. f. Augenheilk., Vol. LXXII, p. 212, 1924.

\section{THE REFRACTION IN CASES OF CONGENITAL TORTICOLLIS ASSOCIATED WITH HEMIATROPHY OF THE FACE}

BY

\author{
ARNOLD SORSBy AND MaRCELli SHAW \\ LONDON
}

AMONG the numberless theories on myopia, the view has been advanced that the myopic eye is the expression of the architecture of the orbit. Stilling and his followers held that low orbits were associated with myopia and high orbits with hypermetropia. The immense literature that grew up on this anthropometric view of myopia led to negative or at the least inconclusive results. SchmidtRimpler held strongly that the orbit accommodates itself to the eye. In anisometropia the orbits were found to be of the same measurement on both sides-a fact that certainly does not lend any 